\title{
Remote Underwater Characterization System - Innovative Technology Summary Report
}

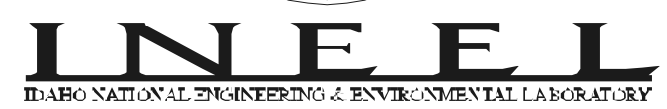

IIAAHO NATIONAL JNGINEERTNG \& EIVIRONMEN'LAI LABORATORY
LOCKHEEDMARTIN

\section{W. D. Willis}

\section{April 1999}

$8^{\text {th }}$ International Topical Meeting on Robotics and Remote Systems - April 25-30, 1999 Pittsburgh, PA

This is a preprint of a paper intended for publication in a journal or proceedings. Since changes may be made before publication, this preprint should not be cited or reproduced without permission of the author.

This document was prepared as a account of work sponsored by an agency of the United States Government. Neither the United States Government nor any agency thereof, or any of their employees, makes any warranty, expressed or implied, or assumes any legal liability or responsibility for any third party's use, or the results of such use, of any information, apparatus, product or process disclosed in this report, or represents that its use by such third party would not infringe privately owned rights. The views expressed in this paper are not necessarily those of the U.S. Government or the sponsoring agency. 


\title{
THE REMOTE UNDERWATER CHARACTERIZATION SYSTEM
}

\author{
Walter D. Willis, Matthew O. Anderson, and Mark D. McKay \\ (Idaho National Engineering and Environmental Laboratory) \\ P.O. Box 1625, MS 2220, Idaho Falls, ID 83415-2220 USA \\ E-mail:ww2@inel.gov
}

Tel: (208) 526-8613

\begin{abstract}
Characterization and inspection of water-cooled and moderated nuclear reactors and fuel storage pools requires equipment capable of operating underwater. Similarly, the deactivation and decommissioning of older nuclear facilities often requires the facility owner to accurately characterize underwater structures and equipment which may have been sitting idle for years. The underwater characterization equipment is often required to operate at depths exceeding $20 \mathrm{ft}(6.1 \mathrm{~m})$ and in relatively confined or congested spaces. The typical baseline approach has been the use of radiation detectors and underwater cameras mounted on long poles, or stationary cameras with pan and tilt features mounted on the sides of the underwater facility. There is a perceived need for an inexpensive, more mobile method of performing close-up inspection and radiation measurements in confined spaces underwater.
\end{abstract}

The Remote Underwater Characterization System (RUCS) is a small, remotely operated submersible vehicle intended to serve multiple purposes in underwater nuclear operations. It is based on the commercially-available "Scallop" vehicle ${ }^{1}$, but has been modified by Department of Energy's Robotics Technology Development Program to add auto-depth control, and vehicle orientation and depth monitoring at the operator control panel. The RUCS is designed to provide visual and gamma radiation characterization, even in confined or limited access areas. It was demonstrated in August 1998 at Idaho National Engineering and Environmental Laboratory (INEEL) as part of the INEEL Large Scale Demonstration and Deployment Project. During the demonstration it was compared in a "head-tohead" fashion with the baseline characterization technology. This paper summarizes the results of the demonstration and lessons learned; comparing and contrasting both technologies in the areas of cost, visual characterization, radiological characterization, and overall operations.

\section{Introduction}

The United States Department of Energy (DOE) continually seeks safer and more cost-effective technologies for use in decontamination and decommissioning (D\&D) of nuclear facilities, and has invested significant funds to develop them. In order to bring these technologies to the field and prove them, the Deactivation and Decommissioning Focus Area (DDFA) of the DOE's Office of Science and Technology sponsors Large-Scale Demonstration and Deployment Projects (LSDDPs). At these LSDDPs developers and vendors of improved or innovative technologies showcase products that are potentially beneficial to the DOE's projects, and to others in the D\&D community. Benefits sought include decreased health and safety risks to personnel and the environment, increased productivity, and decreased cost of operation. 
The INEEL LSDDP generated a list of technology need statements defining specific needs or problems where improved technology could be incorporated into ongoing D\&D tasks. One of the stated needs was the underwater inspection and radiological characterization of surfaces and point sources. Inspection and characterization of water-cooled and moderated nuclear reactors and fuel storage pools requires equipment capable of operating underwater. This equipment is often required to operate at depths exceeding $20 \mathrm{ft}(6.1 \mathrm{~m})$ and in relatively confined spaces. The typical baseline technologies consist of radiation detectors and underwater cameras mounted on long poles, or stationary cameras with pan and tilt capabilities mounted on the sides of the underwater facility. In some cases the only method of underwater viewing during characterization has been a Plexiglas window floating on the surface of the water. One of these Plexiglas windows (wrapped by pink foam) can be seen floating on the surface of the Test Reactor Area Building 660 (TRA-660) canal in Figure 1.

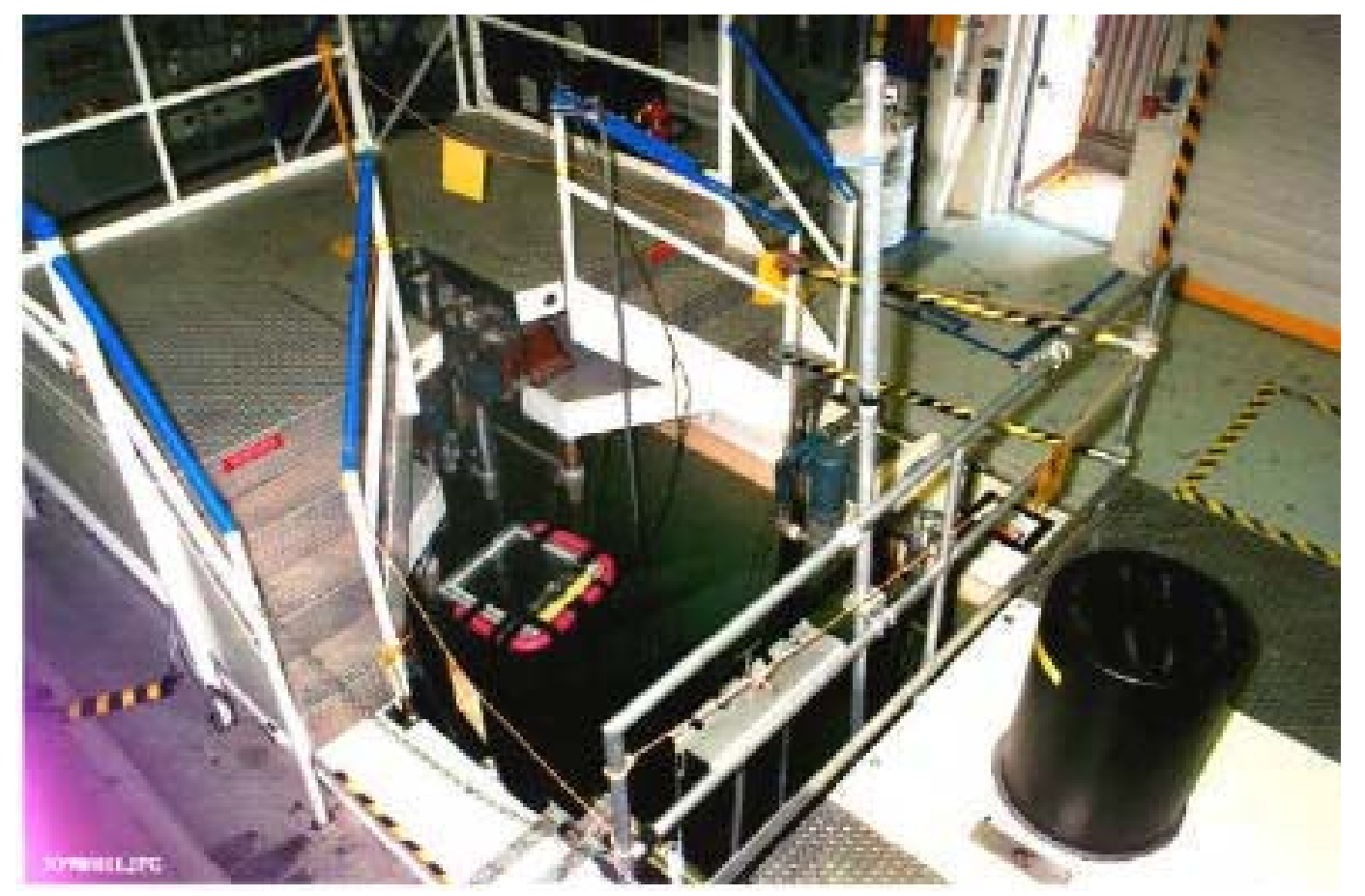

Figure 1. Plexiglas window floating on the surface of the TRA-660 canal

The RUCS demonstration investigated the feasibility of using a small, remotely operated submersible vehicle with an integrated radiation detector as an alternative for performing close-up inspection and radiation measurements in confined spaces underwater. Benefits expected from using the underwater vehicle include:

- Reduced cost of operation

- Increased worker safety

- Enhanced capability

This paper provides a comparative analysis of the cost and performance of the baseline characterization equipment used for underwater characterization and the innovative RUCS technology. 


\section{Technology Summary}

Two different characterization technologies are compared in this paper; the baseline technology and the innovative technology. For clarification, the baseline technology actually requires two separate tools for characterization - an underwater camera and an underwater radiation detector. The innovative technology (RUCS) combines a camera and a detector on a small submersible vehicle.

\subsection{Baseline Technology}

Most DOE facilities with canals or pools have requirements for visual inspection of equipment mounted or stored underwater. When these facilities are prepared for $\mathrm{D} \& \mathrm{D}$, radiological characterization of items in the pools and canals must be performed to dispose of wastes properly and understand the hazards to personnel. Underwater cameras have been used for many years within the DOE complex. Typically, waterproof inspection cameras have been mounted on long poles or attached to the end of a cable. An operator would stand above the area to be inspected to lower and position the camera manually to get the desired view. More recently, the baseline vision system has become a waterproof camera with zoom capability and underwater lights mounted on a waterproof pan and tilt unit. This vision system is mounted on a long, multi-section pole and can be handled and positioned manually (see Figure 2). It can also be fixed or clamped at a central location and then the pan and tilt and zoom capabilities can be operated remotely to provide task surveillance from a single viewpoint.
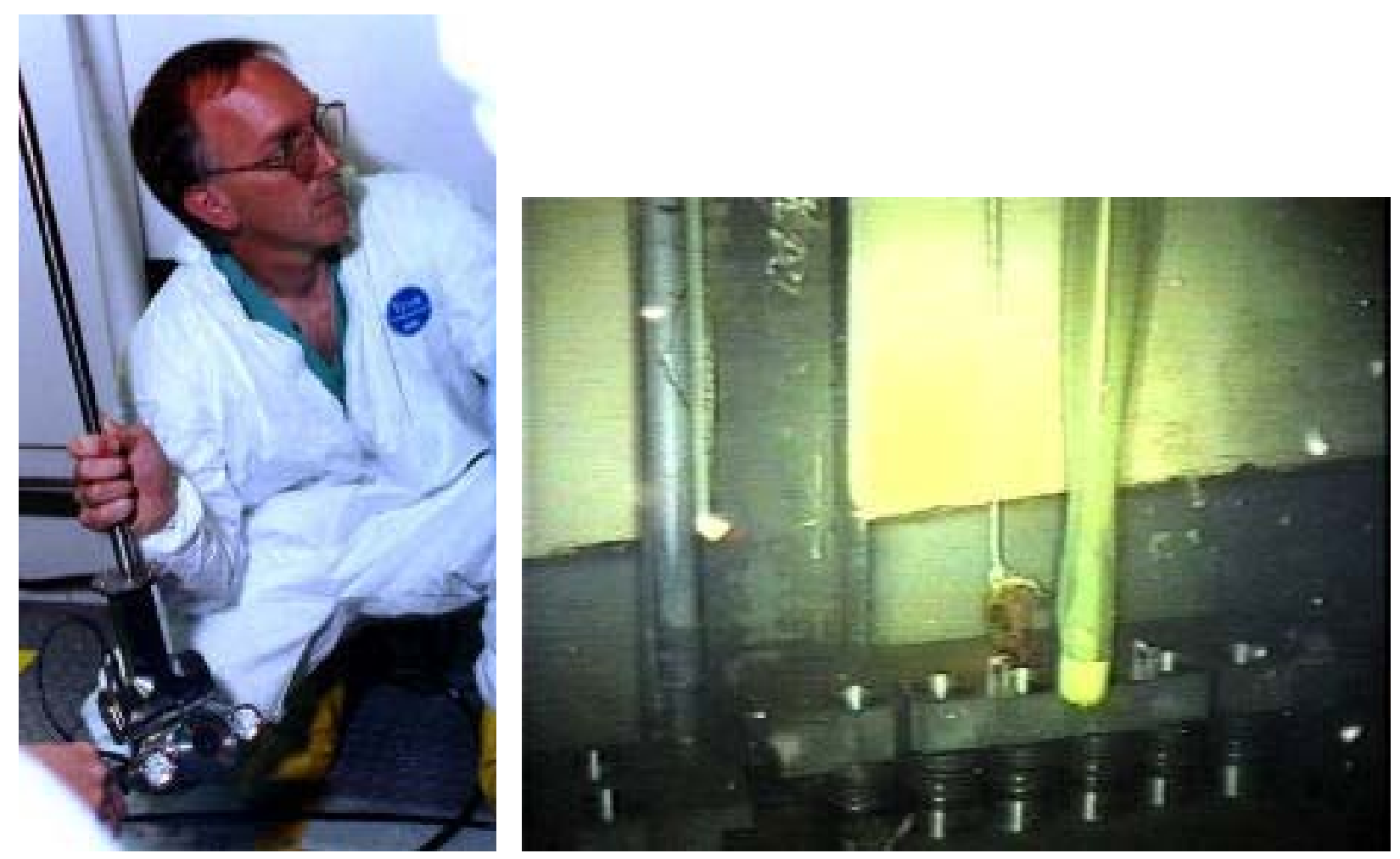

Figure 2. The baseline camera system and the baseline radiation detector (inside plastic sleeve) 
When radiological characterization is performed underwater, it is typically done in much the same manner as the camera deployment, with a radiation detector placed in a waterproof housing and lowered into the water from above (see Figure 2 on previous page). Visual positioning of the radiation detector is accomplished by either looking through the water from above or placing a camera underwater in a suitable location. Often additional lighting must be provided by an underwater light source.

\subsection{Innovative Technology}

The RUCS is a small, remotely operated submersible vehicle intended to serve multiple purposes in underwater D\&D operations (see Figure 3). It is based on the commercially available "Scallop" vehicle produced by Inuktun Services Ltd., British Columbia Canada, but has been modified by DOE's Robotics Technology Development Program. These modifications include:

- Addition of auto-depth control to hold the vehicle at a selected depth.

- Integration of a waterproof radiation detector on the vehicle and a radiation display at the control station.

- Vendor-installed vehicle orientation/heading monitoring via an on-board compass.

- Vendor-installed vehicle depth monitoring at the operator control station.

The RUCS is designed to perform visual inspection and gamma radiation characterization, even in confined or limited access areas. It utilizes a forward-looking tilt color camera and a GM tube radiation detector to get "on-the-spot" information needed to perform D\&D intelligently and safely.

Two integral sub-systems comprise the remotely operated underwater characterization system; the remotely operated underwater vehicle and the operator control station. A $125 \mathrm{ft}(38.1 \mathrm{~m})$ neutral buoyancy tether connects the two sub-systems. The underwater vehicle measures 12 in $\mathrm{X} 9$ in $\mathrm{X} 6$ in $(30 \mathrm{~cm} \mathrm{X} 22.5 \mathrm{~cm} \mathrm{X} 15 \mathrm{~cm})$ and is rated to $100 \mathrm{ft}(30.5 \mathrm{~m})$ of depth. Left and right variable speed horizontal thrusters, which are reversible, are used to turn the vehicle and drive it forward and backward. A single, variable speed vertical thruster is used to drive the vehicle to a desired depth, while slightly positive vehicle buoyancy is used to bring it back to the surface. A depth sensor provides depth information back to the operator control station, and an on-board compass sends heading information back to the operator control station as long as there are not significant amounts of carbon steel present. The vehicle has a forward-looking color camera with tilt capability, a fixed rear-looking black and white camera, and two variable intensity halogen lights for underwater illumination.

The operator control station consists of a single case the size of a standard suitcase. All vehicle controls are operable from the control station. A proportional joystick is used to "fly" the vehicle in the horizontal plane, and a rotary knob is used to adjust vertical thruster speed and thereby adjust vehicle depth. Another rotary knob is used to control light output, and there are controls to tilt and focus the forward-looking color camera. The "auto-depth" feature acts much like a cruise control to allow the operator to hold the vehicle at a selected depth. A relatively simple circular array of light-emitting diodes indicates the vehicle's heading. A small digital display shows the measured radiation reading (5 $\mathrm{mR} / \mathrm{hr}$ up to $999 \mathrm{R} / \mathrm{hr}$ ) from the radiation sensor. A coax video plug allows the operator to display and/or record the video signal from the vehicle cameras and a switch on the console allows switching between the front and rear cameras. 

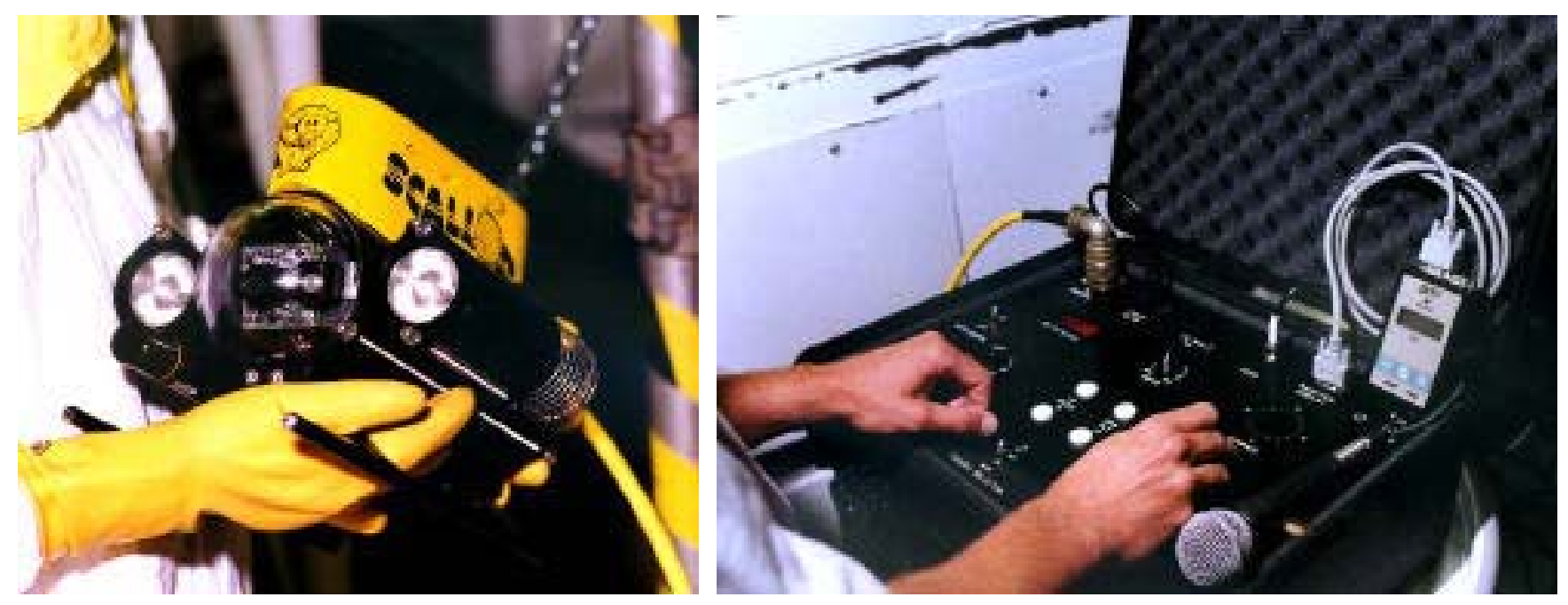

Figure 3. The RUCS vehicle and control station

\section{Demonstration Summary}

The baseline technology was demonstrated on August 24, 1998 and the RUCS was demonstrated on August 25, 1998 at the INEEL. The test area for the demonstration was the canal in the TRA-660 facility (see Figure 4$)$. The canal itself is $8 \mathrm{ft}(2.4 \mathrm{~m})$ wide, $18 \mathrm{ft}(5.5 \mathrm{~m})$ deep and $28 \mathrm{ft}(8.5 \mathrm{~m})$ long. A 4 $\mathrm{ft}(1.2 \mathrm{~m})$ by $8 \mathrm{ft}(2.4 \mathrm{~m})$ storage pit at the center of the canal extends down an additional $5 \mathrm{ft}(1.5 \mathrm{~m})$. The canal can be drained by transferring water to the TRA warm waste treatment system, but there is no water cleanup or filtering system. The canal was originally built as a fuel storage canal and now holds two small, de-fueled test reactors. The two reactors are located about $15 \mathrm{ft}(4.6 \mathrm{~m})$ apart at either end of the common water canal. The two reactors are very similar physically, consisting of a control bridge, lattice support frame, and grid plates. These components are suspended from the canal parapet. The control bridges are made of steel I-beams and plates. The top of the active core is $12 \mathrm{ft}(3.6 \mathrm{~m})$ below the water surface. In addition to the reactors, there is also a neutron radiography structure in the center of the canal, and various other pieces of hardware and miscellaneous components lying on the floor of the canal or hung from the side. No accurate or comprehensive radiological characterization of the interior of the canal, including the reactors and other hardware, had been performed prior to the RUCS demonstration.

\subsection{Major Objectives of the Demonstration}

The RUCS was evaluated against the baseline technology in the areas of cost effectiveness, ability to provide a safer work environment, enhanced capability, and limitations. Both the baseline technologies and the RUCS were used to visually survey the canal and its contents, and also to gather radiological characterization data on the reactors and equipment on the floor of the canal (see Figure 5). The activities and areas surveyed were kept as identical as possible to provide valid comparative data. 


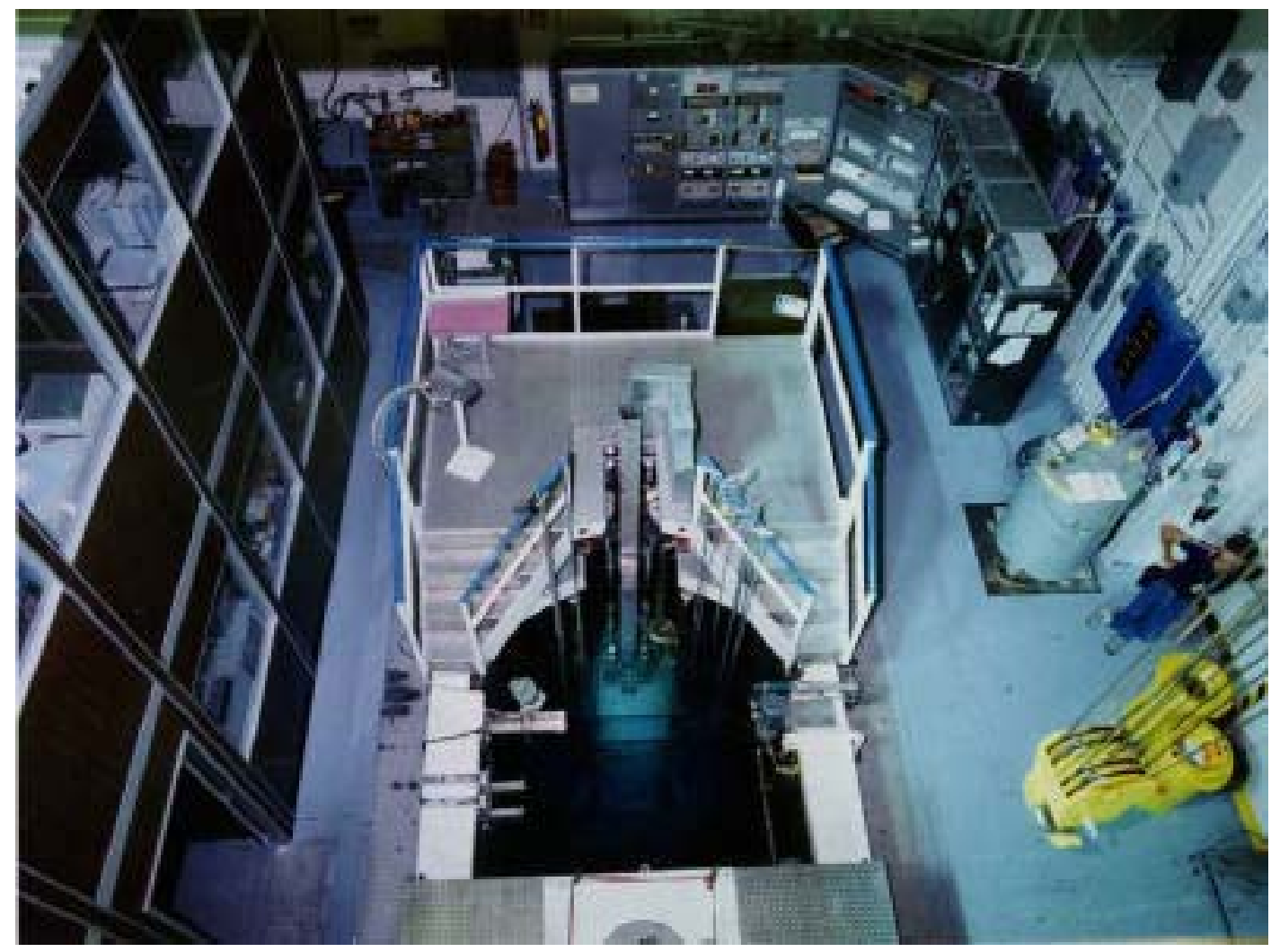

Figure 4. Overhead view of the south end of the TRA-660 canal

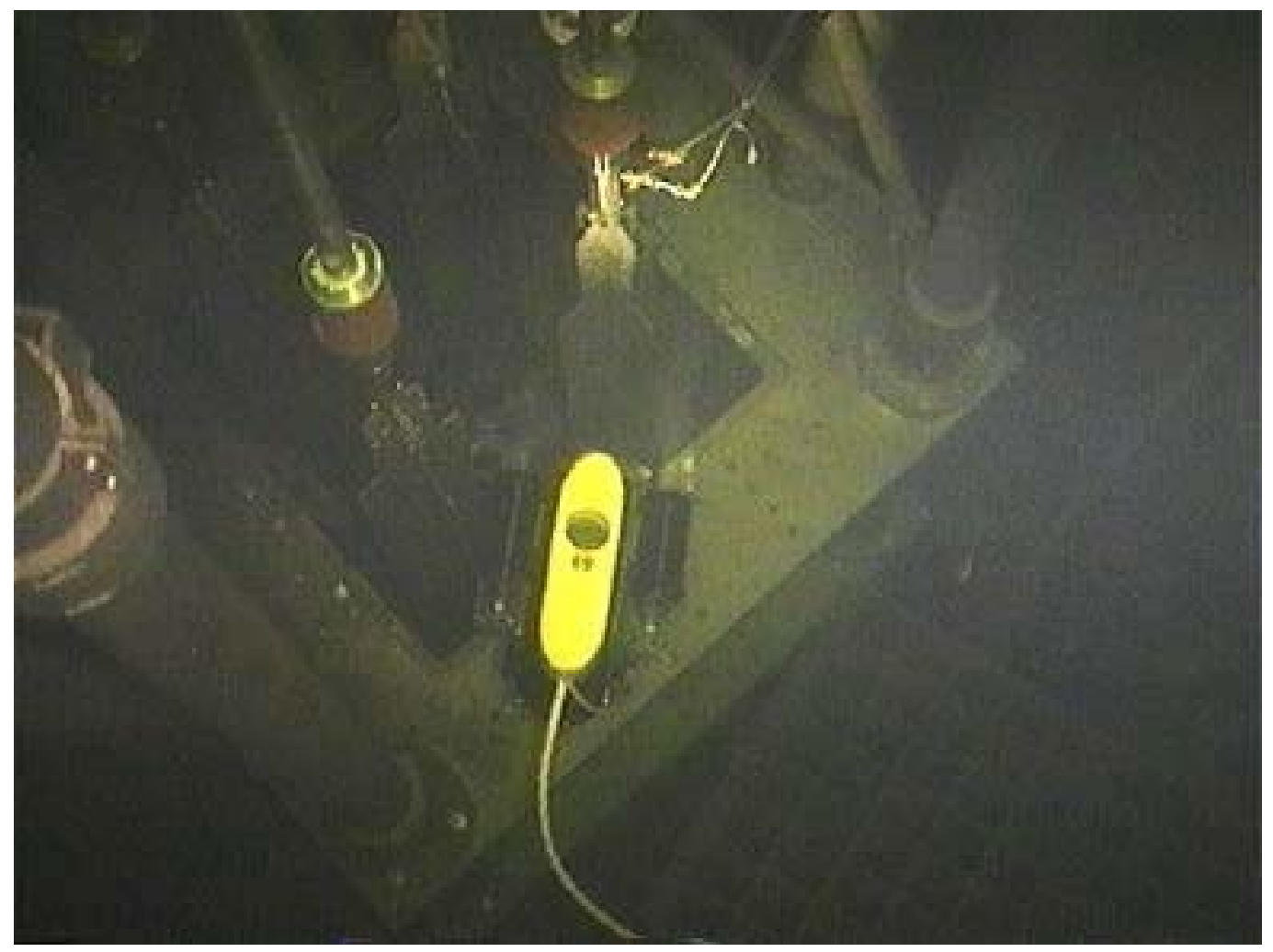

Figure 5. The RUCS vehicle characterizing a control rod 


\subsection{Major Elements of the Demonstration}

Both the baseline technology and the RUCS were used to perform a "typical" characterization of the canal. The intent of the characterization was to gather information the owner of the facility needed to make intelligent decisions regarding D\&D activities such as packaging, segregating, and priority of removal. The RUCS demonstration included visual characterization of the condition and contents of the canal as well as radiological characterization of items suspected to be radioactively activated. The common elements of the demonstration included:

- Visual characterization of north reactor condition

- Visual characterization of the north end of the canal, particularly the floor

- Radiological characterization of the accessible areas of the north reactor

- Radiological characterization of the items on the floor of the north end of the canal including upper grid plate assemblies

- Visual characterization of south reactor condition

- Visual characterization of the south end of the canal, particularly the floor

- Radiological characterization of the accessible areas of the south reactor

- Radiological characterization of the items on the floor of the north end of the canal including upper grid plate assemblies, stainless steel bucket, rusted bucket, fuel storage grid

In addition, the following activities were performed during the course of the demonstration:

- Determine if the baseline technology had the ability to access areas and gather information that the RUCS could not.

- Determine if the RUCS had the ability to access areas and gather information that the baseline technology could not.

- Identify limitations and benefits of both the baseline technology and the innovative technology

\subsection{Performance Comparison}

Both characterization technologies were evaluated under identical physical conditions. Every attempt was made to allow work to proceed under normal conditions with no bias. All parties involved in the demonstration were requested to perform the work casually with no special emphasis on speed or efficiency. The baseline technology was demonstrated on Monday and the RUCS was evaluated on Tuesday of the same week. The tasks performed were basically identical, but not all the objects and locations characterized were completely identical. In addition to the similar tasks, the RUCS was used to characterize several areas inaccessible to the baseline technology, and the baseline technology was used to take radiation readings in some locations inaccessible to the RUCS radiation detector. A performance comparison between the two technologies is listed in Table 2. 
Table 2: Performance comparison between the RUCS and the baseline technology

\begin{tabular}{|c|c|c|}
\hline Performance Factor & Baseline Technology & RUCS \\
\hline $\begin{array}{l}\text { Number of } \\
\text { personnel required } \\
\text { in canal } \\
\text { contamination area }\end{array}$ & $\begin{array}{l}\text { 2 } 2 \text { to } 3 \text { people } \\
\text { (2 workers to manage and move } \\
\text { camera, 1 Radiological Control } \\
\text { Technician (RCT) to operate RO7 } \\
\text { detector. RCT could replace 1 worker) }\end{array}$ & $\begin{array}{l}1 \text { person } \\
\text { (1 worker to manage tether and put } \\
\text { RUCS vehicle in and out of canal) }\end{array}$ \\
\hline $\begin{array}{l}\text { Number of } \\
\text { personnel required } \\
\text { outside } \\
\text { contamination area }\end{array}$ & $\begin{array}{l}\text { 2 people } \\
\text { (1 worker to operate camera controls, } \\
1 \text { RCT to monitor radiation readings } \\
\text { and survey equipment out of } \\
\text { contamination area) }\end{array}$ & $\begin{array}{l}\text { 2 people } \\
\text { (1 worker to operate RUCS, } 1 \text { RCT to } \\
\text { survey equipment out of contamination } \\
\text { area) }\end{array}$ \\
\hline $\begin{array}{l}\text { Time to assemble } \\
\text { and deploy } \\
\text { technology }\end{array}$ & Approx. $10 \mathrm{~min}$ & Approx. 5 min. \\
\hline Quality of video & $\begin{array}{c}\text { Excellent } \\
\text { (S-VHS, }>460 \text { Lines) }\end{array}$ & $\begin{array}{c}\text { Very Good } \\
(\text { NTSC, 480 lines) } \\
\end{array}$ \\
\hline $\begin{array}{l}\text { Number of radiation } \\
\text { readings per hour } \\
\text { (avg.) }\end{array}$ & $\begin{array}{c}22.6 \\
\text { (Could be slightly lower, survey points } \\
\text { were fairly close together) } \\
\end{array}$ & $\begin{array}{c}21.6 \\
\text { (Could be slightly higher, survey points } \\
\text { were moderately separated) }\end{array}$ \\
\hline $\begin{array}{l}\text { Resolution of } \\
\text { radiation readings }\end{array}$ & $\begin{array}{l}\qquad 100 \mathrm{mR} / \mathrm{hr} \text { to } 200 \mathrm{R} / \mathrm{hr} \\
\text { (Range depends on sensor head used. } \\
\text { Three different sensor heads are } \\
\text { available.) }\end{array}$ & $5 \mathrm{mR} / \mathrm{hr}$ to $1000 \mathrm{R} / \mathrm{hr}$ \\
\hline $\begin{array}{l}\text { Personal Protective } \\
\text { Equipment (PPE) } \\
\text { requirements }\end{array}$ & \multicolumn{2}{|c|}{$\begin{array}{l}\text { Both technologies required the same level of PPE. Total PPE used with the } \\
\text { RUCS was lower because of fewer workers needed in the contamination area. }\end{array}$} \\
\hline Superior capability & $\begin{array}{l}\text { The baseline radiation detector could } \\
\text { be lowered into vertical spaces, such as } \\
\text { the holes where the fuel had been. } \\
\text { This provided better radiation data } \\
\text { than the RUCS could provide. }\end{array}$ & $\begin{array}{l}\text { The RUCS was more maneuverable } \\
\text { than the baseline technology and } \\
\text { could get into areas inaccessible to } \\
\text { the baseline. These areas included } \\
\text { the } 1 \mathrm{ft} \text { wide space behind the } \\
\text { reactors, and the deeper section of } \\
\text { the canal beneath overhead } \\
\text { structure. } \\
\text { The RUCS radiation detector could } \\
\text { be driven next to objects, even if } \\
\text { overhead obstructions were present. } \\
\text { One example was a bucket with a } \\
\text { large block resting on top of it. The } \\
\text { RUCS provided better radiation data } \\
\text { than the baseline could provide. } \\
\text { The RUCS was generally easier to } \\
\text { use, particularly when trying to get } \\
\text { information from areas separated by } \\
\text { the bridge across the center of the } \\
\text { canal. Assembly and disassembly was } \\
\text { also simpler. }\end{array}$ \\
\hline
\end{tabular}




\section{Key Results/Lessons Learned}

The key results of the RUCS demonstration are summarized below:

- The RUCS reduced overall costs by approximately $40 \%$ when compared to the baseline technology according to a detailed U.S. Army Corps of Engineers cost evaluation.

- The RUCS increased worker safety because fewer personnel had to be present in the contamination/canal area.

- The RUCS was able to characterize many areas more effectively than the baseline technology, and could access some areas that were inaccessible to the baseline technology.

- The RUCS reduced waste because less personal protective equipment was required to perform the work.

\subsection{Implementation Considerations}

The RUCS is a mature technology that performed very well during the INEEL demonstration. There are some very minor improvements that could be made to enhance its operation and effectiveness. These minor improvements are listed in the Technology Limitations portion of this section.

The RUCS does require some small measure of skill to operate. Most of the controls are quite intuitive, but it is recommended that operators have 1 to 2 hours of operating time before operating the RUCS in very confined or congested areas. It is not absolutely necessary to have a person managing the RUCS tether during its operation, but it was helpful during this demonstration and is highly recommended.

\subsection{Technology Limitations and Needs for Future Development}

The RUCS performed well during this demonstration. The only significant technology limitation was the inability of the system to gather radiological characterization data from inside vertical pipes and tubes. This is due to the fixed horizontal orientation of RUCS radiation detector and the overall size of the vehicle. It is doubtful that this limitation could be addressed easily.

There is a need for some minor development work in the following areas:

- The vehicle would maneuver even better if the tether were neutrally buoyant in fresh water. The tether on the RUCS as demonstrated was neutrally buoyant in salt water, which meant it sank slightly in fresh water. This was not a significant limitation in the demonstration, but it did have a slight effect on maneuverability and would have had a more negative effect if the vehicle were operating with $50 \mathrm{ft}(15.3 \mathrm{~m})$ or more of tether in the water. Inuktun now says it can provide a tether that is very nearly neutrally buoyant in fresh water.

- It was noticed that the radiation sensor was pushed back approximately one inch during the course of the demonstration. It is mounted in a pair of friction clips and apparently was moved 
when the vehicle contacted items while taking radiation readings. This is not serious, but the radiation sensor should be secured to prevent horizontal motion

- It would be advisable to develop a way to display radiation readings on the video monitor so that they could be recorded with the video. During the demonstration a microphone was hooked to the video recorder and radiation readings were put on the tape audibly.

\subsection{Technology Selection Considerations}

Based on the INEEL demonstration, the RUCS is better suited than the baseline technology for most underwater viewing and characterization activities. It is easier to deploy, requires fewer workers to operate, has better maneuverability, and is less expensive to operate on a per job basis. There are a couple of instances where the baseline technology would be preferable:

- The baseline radiation detector is the best choice if radiological characterization information is needed from inside a vertical tube or an array of vertical tubes.

- The baseline vision system supplied a slightly higher quality video picture, which could conceivably be important in some instances.

- The baseline vision system might be more desirable if there are large amounts of fine sediment present. The TRA-660 canal had approximately $1 / 4-1 / 2$ in $(.63-1.3 \mathrm{~cm})$ of sludge on the bottom, but it rarely affected visibility significantly, even when the RUCS vehicle was operated right on the canal floor.

\section{ACKNOWLEDGEMENTS}

This demonstration/deployment would not have been accomplished without the dedicated efforts of Glenn Rodman and Bob Graefe at the INEEL Test Reactor Area. The authors salute their perseverance. The authors would like to acknowledge the tremendous cooperation received from Terry Knight and the staff at Inuktun Services while making modifications to their product. The authors would also like to thank Jim Kost at MGP Instruments for his support during the integration of the radiation detector.

\section{REFERENCES}

1. http://www.inuktun.com/ scallop.htm 